\title{
Natural evolution of sleep apnoea syndrome: a five year longitudinal study
}

\author{
E. Sforza, G. Addati, F. Cirignotta, E. Lugaresi
}

Natural evolution of sleep apnoea syndrome: a five year longitudinal study. E. Sforza, G. Addati, F. Cirignotta, E. Lugaresi. CERS Journals Ltd 1994.

ABSTRACT: We wanted to investigate the natural evolution of Obstructive Sleep Apnoea Syndrome (OSAS).

We therefore followed 58 patients who refused any treatment at the time of diagnosis. Of the eligible patients 32 subjects enrolled in instrumental follow-up. The effects on daytime somnolence, daytime lung function and nocturnal respiratory disturbances were retrospectively evaluated by repeating Multiple Sleep Latency Test (MSLT), spirometry and polysomnography after a follow-up period of at least 5 years (5.7 \pm 0.2 SEM yrs).

In the patient group as a whole the mean Apnoea+Hypopnoea Index (AHI), the mean low arterial oxygen saturation $\left(\mathrm{SaO}_{2}\right)$ and the mean Body Mass Index (BMI) did not change over time. The only significant differences were the increase in mean duration of apnoeas (21.0 vs $23.5 \mathrm{~s})$ and hypopneas (13.5 vs $16.3 \mathrm{~s})$ and the decrease in AHI $<80 \%$ (13.3 vs 7.9). No correlations were found between the changes in AHI or mean low $\mathrm{SaO}_{2}$ and age, BMI, AHI, mean low $\mathrm{SaO}_{2}$, pulmonary function tests or arterial blood gases at baseline. No significant changes were observed in systemic blood pressure, pulmonary function tests, blood gases analysis or MSLT. "Improved" $(n=6)$ and "worsened" (n=7) groups were defined by a reduction or increase in AHI over $35 \%$ of baseline value. At baseline the "worsened" group tended to have lower AHI and higher mean low $\mathrm{SaO}_{2}$ compared with the "improved" group. In the "worsened" group the BMI rose significantly from 26.0 to 29.2 , AHI rose significantly from 14.1 to 51.3 and mean low $\mathrm{SaO}_{2}$ decreased from 92 to 90 (Ns). In this subgroup the increase in AHI was not significantly correlated with the gain in BMI.

Our results suggest that: 1) No significant changes in apnoea frequency or nocturnal hypoxaemia occur in the long-term evolution of untreated OSAS patients in the absence of changes in BMI and pulmonary function. 2) Severity of the syndrome and daytime parameters at baseline evaluation did not predict the evolution of the syndrome. 3) Weight gain does not contribute significantly to OSA syndrome exacerbation.

Eur Respir J., 1994, 7, 1765-1770.
Sleep Center, Institute of Neurology, University of Bologna, Italy.

Correspondence: E. Sforza

Clinica Neurologica

Via Foscolo 7

I-40123 Bologna

Italy

Keywords: Long-term study natural history

sleep apnoea syndrome

Received: January 81993

Accepted after revision August 81993
There is some evidence that patients with obstructive sleep apnoea syndrome (OSAS) are at increased risk of cardiovascular morbidity and mortality, compared with the nonapnoeic population [1]. The causal relationship between both diseases is, however, unknown. It is controversial whether the cardiovascular risk is part of the natural progression of the disease, or whether it develops only in certain patients [2]. Several studies have shown that age and weight rather than apnoea index and oxygen desaturation are primary correlates of blood pressure in OSAS patients [3]. One hypothesis is that age and weight may influence the number of apnoeas and the severity of nocturnal oxygen desaturation.

Long-term retrospective studies showed that treatment is essential even in mild or asymptomatic patients with OSAS, because the survival rate decreases in untreated or conservatively treated patients $[4,5]$. Unfortunately, no firm conclusion can be drawn from prospective studies following patients with mild or severe sleep apnoea over time, because of the small number of patients so far studied [6].

In this study, we analysed longitudinally a group of untreated patients for at least 5 yrs after the first examination. Firstly, we describe the natural course of sleep apnoea syndrome, and then we identify the diurnal and/ or nocturnal variables that contribute to syndrome progression.

Methods and patients

\section{Patients}

We reviewed the polysomnographic data of 100 patients with a discharge diagnosis of OSAS made between 1984 and 1987 . Only those subjects whose diagnostic study comprised nocturnal polysomnography followed by 
multiple sleep latency test (MSLT) and pulmonary function tests, without any therapeutic intervention, were included. Patients with previous weight loss or surgery were excluded. Of the 58 eligible patients, 32 subjects ( 29 males and 3 females) enrolled in instrumental follow-up evaluation. The other 26 subjects ( 24 males and 2 females) refused polygraphic study, but agreed to clinical interview.

\section{Investigation}

At baseline and at follow-up evaluation, all patients answered questions about sleepiness, snoring and hypertension, and had a full evaluation, including measurement of blood pressure, nocturnal polysomnography followed by MSLT and respiratory function tests. Unfortunately, no quantitative information on drug intake and alcohol consumption was available at the time of the diagnosis. All-night sleep studies included electroencephalogram (EEG), electrooculogram (EOG), submental and intercostal surface electromyogram (EMG) and electrocardiogram (ECG). Nasal and oral airflow were monitored with a thermistor, and chest and abdominal wall movements were detected using a strain gauge. Arterial oxygen saturation $\left(\mathrm{SaO}_{2}\right)$ was measured continuously by ear oximeter (Ohmeda Biox III). Snoring was measured using a tracheal microphone. Body position was determined by monitoring the patient on a closed circuit television, and changes in posture were marked as they occurred. On the day following nocturnal study, MSLT was performed using standard criteria.

\section{Analysis}

The analysis of sleep and respiratory events was performed by a single scorer (ES), to avoid possible errors due to different subjective estimates. Sleep was scored using the method of RechtschafFen and Kales [7]. Sleep efficiency (SE) was calculated as total sleep time/total recording time. Central, mixed and obstructive apnoeas were defined, according to standard criteria. Hypopnoeas were defined by an estimated $50 \%$ or more reduction in the oronasal airflow, associated with at least a $4 \%$ decrease in oxygen saturation.

Snoring was quantified by recording its frequency, expressed as the snoring index (SI: number of epochs with snores exceeding $50 \%$ of the epoch per hour of sleep). The following indices were computed: the apnoea index (AI: number of apnoeas per hour of sleep); the hypopnoea index (HI: number of hypopnoeas per hour of sleep); the apnoea+hypopnoea index (AHI: number of apnoeas and hypopnoeas per hour of sleep); the apnoea+hypopnoea index in a supine position (AHIS: number of apnoeas and hypopnoeas per hour of sleep spent in supine position); the apnoea+hypopnoea index in a lateral position (AHIL: number of apnoeas and hypopnoeas per hour of sleep spent in lateral position); the $<90 \%$ apnoea+hypopnoea index (AHI<90\%: number of apnoeas and hypopnoeas with $\mathrm{SaO}_{2}<90 \%$ per hour of sleep), the $<80 \%$ apnoea+hypopnoeas index $(\mathrm{AHI}<80 \%$ : number of apnoeas and hypopnoeas with $\mathrm{SaO}_{2}<80 \%$ per hour of sleep) and the apnoea time (time of sleep spent in apnoea).

The following $\mathrm{SaO}_{2}$ indices were also defined: mean $\mathrm{SaO}_{2}$ during 10 min of wakefulness $\left(\mathrm{WSaO}_{2}\right)$ prior to sleep onset; mean minimal $\mathrm{SaO}_{2}$ after each event (mean Low $\mathrm{SaO}_{2}$ ); and the mean $\mathrm{SaO}_{2}$ during snoring $\left(\mathrm{SaO}_{2} \mathrm{Snor}\right)$.

In addition, we examined three subgroups of patients, formed on the basis of the AHI changes between the two conditions: 1) with a reduction of at least $35 \%$ of $\mathrm{AHI}$ ("improved", $n=6$ ); 2) with an increase of at least $35 \%$ of AHI ("worsened", n=7); and 3) including the other patients ("stable", n=19).

\section{Statistics}

Statistical significance for the groups accepting and refusing follow-up was assessed by simple Student's test. Differences between baseline and follow-up for the entire group of patients accepting follow-up and for the subgroups of worsened, improved and stable patients were compared using Student's t-test for paired data. In order to investigate the determinants of the changes, correlations were calculated between the differences before and at follow-up, and various diurnal and nocturnal parameters, using a multiple regression analysis. The null hypothesis was rejected at a level of $\mathrm{p} \leq 0.05$. Data reported in the text and figures are expressed as mean \pm SEM.

\section{Results}

\section{Baseline evaluation}

The clinical and nocturnal respiratory parameters for the group of patients either accepting or refusing instrumental follow-up are reported in table 1.

Table 1. - Clinical and nocturnal respiratory parameters in OSAS patients accepting and refusing instrumental follow-up

\begin{tabular}{|c|c|c|}
\hline & $\begin{array}{c}\text { Accepting } \\
\mathrm{n}=32\end{array}$ & $\begin{array}{c}\text { Refusing } \\
\mathrm{n}=26\end{array}$ \\
\hline Age yrs & $51 \pm 1.8$ & $48 \pm 2.2$ \\
\hline $\mathrm{BMI} \mathrm{kg} \cdot \mathrm{m}^{-2}$ & $30.7 \pm 1.1$ & $34.2 \pm 1.9^{*}$ \\
\hline SBP $\mathrm{mmHg}$ & $143 \pm 3.3$ & $143 . \pm 2.6$ \\
\hline DBP $\mathrm{mmHg}$ & $91 \pm 2.7$ & $91 \pm 2.8$ \\
\hline \multirow{2}{*}{$\mathrm{PaO}_{2} \underset{\mathrm{kPa}}{\mathrm{mmHg}}$} & $81.5 \pm 2.0$ & $82.5 \pm 2.3$ \\
\hline & $10.9 \pm 0.3$ & $11.0 \pm 0.3$ \\
\hline \multirow{2}{*}{$\begin{array}{ll}\mathrm{PaCO}_{2} & \mathrm{mmHg} \\
\mathrm{kPa}\end{array}$} & $38.7 \pm 0.8$ & $38.3 \pm 0.8$ \\
\hline & $5.2 \pm 0.1$ & $5.1 \pm 0.1$ \\
\hline FVC $l$ & $3.68 \pm 0.14$ & $3.70 \pm 0.15$ \\
\hline $\mathrm{FEV}_{1} l$ & $2.86 \pm 0.11$ & $2.89 \pm 0.14$ \\
\hline $\mathrm{FEV}_{1} / \mathrm{FVC} \%$ & $78 \pm 0.79$ & $78 \pm 0.80$ \\
\hline AHI $n \cdot h^{-1}$ & $52.2 \pm 6.0$ & $43.2 \pm 7.1$ \\
\hline Mean dur $\mathrm{s}$ & $19.9 \pm 1.2$ & $21.0 \pm 1.4$ \\
\hline Mean low $\mathrm{SaO}_{2} \%$ & $86 \pm 1.5$ & $85 \pm 1.6$ \\
\hline MSLT $\min$ & $6.1 \pm 0.8$ & $7.5 \pm 1.0$ \\
\hline
\end{tabular}

Data are presented as mean \pm SEM. $*: p=0.05$. OSAS: obstructive sleep apnoea syndrome; BMI: body mass index; SBP: systolic blood pressure; DBP: diastolic blood pressure; $\mathrm{PaO}_{2}$ : arterial oxygen tension; $\mathrm{PaCO}_{2}$ : arterial carbon dioxide tension; $\mathrm{FVC}$ : forced vital capacity; $\mathrm{FEV}_{1}$ : forced expiratory volume in one second; AHI: apnoea+hypopnoea index; Mean dur: mean apnoea and hypopnoea duration; Mean low $\mathrm{SaO}_{2}$ : mean low arterial oxygen saturation during apnoeas and hypopnoeas; MSLT: mean sleep latency at the multiple sleep latency test; ns: nonsignificant. 
Daytime data. At baseline, the mean age of the group of patients accepting instrumental re-evaluation was $51 \pm 1.8$ yrs (range 67-28 yrs), and the mean BMI 30.7 \pm 1.1 (range 40.6-21.0). According to a systolic blood pressure reading of $\geq 150 \mathrm{mmHg}$ or a diastolic value of $\geq 90 \mathrm{mmHg}$ or previous antihypertensive treatment, as criteria for the definition of systemic hypertension, 10 subjects were hypertensive. Three patients had resting hypoxaemia, defined as an arterial oxygen tension $\left(\mathrm{PaO}_{2}\right) \leq 65 \mathrm{mmHg}(8.7 \mathrm{kPa})$, and none had hypercapnia, defined as arterial carbon dioxide tension $\left(\mathrm{PaCO}_{2}\right) \geq 45 \mathrm{mmHg}(6.0 \mathrm{kPa})$. Two subjects had diffuse airway obstruction, defined as a forced expiratory volume in one second as percentage of forced vital capacity $\left(\mathrm{FEV}_{1} / \mathrm{FVC} \%\right) \leq 65 \%$. In the group of patients who refused follow-up investigations, the mean age was $48 \pm 2.2$ yrs (range 64-21 yrs), and BMI 34.2 \pm 1.9 (range 58.5-20.6). Seven subjects were hypertensive, two hypoxaemic and one hypercapnic. As shown in table 1, there were no statistical differences in diurnal parameters between patients who agreed to follow-up and those refusing instrumental evaluation, except for BMI $(\mathrm{p}=0.05)$.

Polysomnographic data. All subjects in the group of follow-up patients, had predominantly obstructive (67\%), and mixed $(27 \%)$, apnoeas, with sporadic central apnoeas $(3 \%)$ in some patients. The total frequency of sleeprelated respiratory events covered a wide range of severity. Five patients were snorers, defined by an AHI $<10$, with an SI of $22.6 \pm 1.7$, and a snoring $\mathrm{SaO}_{2}$ of $95 \pm 1.9 \%$. Two patients had mild apnoea syndrome defined by an AHI $<20$, eight moderate (AHI $>20<50$ ), and 17 severe $(\mathrm{AHI}>50)$. The mean duration of respiratory events was $19.9 \pm 1.2 \mathrm{~s}$, and the mean low $\mathrm{SaO}_{2} 86 \pm 1.5 \%$. Daytime sleepiness was confirmed by the presence of a mean sleep latency of 6.1 min during MSLT; 16 subjects had pathological sleepiness (MSLT $<5 \mathrm{~min}$ ), and eight a borderline value ( $5 \mathrm{~min}>$ MSLT $<10 \mathrm{~min}$ ).

In the group refusing follow-up, the AHI was 43.2 (range 5.1-128.8), with a mean low $\mathrm{SaO}_{2}$ of $85 \%$ (range 67-94\%), and a mean duration of $21 \mathrm{~s}$ (range 17-37 s). Two patients were snorers, five mild OSAS and seven severe. The mean sleep latency was $7.5 \mathrm{~min}$ at the MSLT; nine patients had pathological sleepiness and nine borderline.

\section{Follow-up evaluation}

Daytime data. Table 2 shows the anthropometric, clinical and pulmonary function tests data for the set of patients accepting follow-up, at baseline and after at least 5 yrs.

All patients reported an improvement in subjective symptoms, particularly in diurnal sleepiness and apnoea. Four patients developed diurnal systemic hypertension, and three patients cardiological diseases (one myocardial ischaemia and two arrhythmias). In the group of patients who refused polygraphic study, an improvement in sleepiness and apnoea was referred, without changes in weight (BMI 34.2 v 34.5). In this group, two patients developed hypertension and/or myocardial ischaemia. No death was reported in either group.

In the follow-up group, there were no significant changes in anthropometric data. In particular, the BMI remained
Table 2. - Clinical and anthropometric data at baseline and follow-up in the group of accepting patients $(n=32)$

\begin{tabular}{|c|c|c|}
\hline & Baseline & Follow-up \\
\hline Age yrs & $51 \pm 1.8$ & $57 \pm 1.7 \dagger$ \\
\hline BMI $\mathrm{kg} \cdot \mathrm{m}^{-2}$ & $30.7 \pm 1.1$ & $31 \pm 1.0$ \\
\hline $\mathrm{SBP} \mathrm{mmHg}$ & $143 \pm 3.3$ & $143 \pm 2.6$ \\
\hline DBP mmHg & $91 \pm 2.7$ & $87 \pm 1.9$ \\
\hline $\mathrm{PaO}_{2} \mathrm{mmHg}$ & $81.5 \pm 2.0$ & $80.9 \pm 2.6$ \\
\hline $\mathrm{kPa}$ & $10.9 \pm 0.3$ & $10.8 \pm 0.3$ \\
\hline $\mathrm{PaCO}_{2} \mathrm{mmHg}$ & $38.7 \pm 0.8$ & $40.3 \pm 0.7$ \\
\hline $\mathrm{kPa}$ & $5.2 \pm 0.1$ & $5.4 \pm 0.1$ \\
\hline $\mathrm{FEV}_{1} l$ & $2.86 \pm 0.11$ & $2.80 \pm 0.11$ \\
\hline $\mathrm{FVC} l$ & $3.68 \pm 0.14$ & $3.61 \pm 0.12$ \\
\hline $\mathrm{FEV}_{1} / \mathrm{FVC} \%$ & $78 \pm 0.79$ & $77 \pm 1.12$ \\
\hline
\end{tabular}

Data are presented as mean \pm SEM. $\dagger: \mathrm{p} \geq 0.001$. For abbreviations see legend to table 1 .

unchanged in the group as a whole; only eight showed an increase. Smoking habits were unchanged during the study, except in eight patients who stopped smoking.

No significant changes were observed in diurnal systemic pressure in normotensive and hypertensive subjects. $\mathrm{PaO}_{2}, \mathrm{PaCO}_{2}$ and pulmonary function tests did not change significantly over the $5 \mathrm{yr}$ period.

Polysomnographic data. The sleep and respiratory sleep disturbances at baseline and follow-up are reported in table 3. All subjects had poor sleep quality, as evidenced by the reduction in slow wave sleep, the decrease in sleep efficiency and the increase in number of arousals. These sleep alterations were more marked at the follow-up, particularly for sleep efficiency.

There were no significant changes in nocturnal respiratory parameters (table 3 ) in the group of patients as a whole.

Table 3. - Baseline and follow-up polysomnographic data $(\mathrm{n}=32)$

\begin{tabular}{|c|c|c|}
\hline & Baseline & Follow-up \\
\hline SE $\%$ & $79 \pm 1.7$ & $74 \pm 2.5^{*}$ \\
\hline Light sleep \% & $83 \pm 1.8$ & $84 \pm 1.7$ \\
\hline Slow sleep \% & $5.6 \pm 1.1$ & $5.0 \pm 1.1$ \\
\hline REM sleep \% & $11.1 \pm 1.1$ & $11.5 \pm 0.9$ \\
\hline MSLT min & $6.1 \pm 0.8$ & $7.1 \pm 0.8$ \\
\hline $\mathrm{SaO}_{2}$ Wake \% & $94 \pm 0.4$ & $94 \pm 0.3$ \\
\hline AI $n \cdot h^{-1}$ & $45.3 \pm 6.0$ & $43.5 \pm 5.1$ \\
\hline HI $n \cdot h^{-1}$ & $6.9 \pm 1.2$ & $8.7 \pm 1.5$ \\
\hline AHI $n \cdot h^{-1}$ & $52.2 \pm 6.0$ & $52.2 \pm 4.8$ \\
\hline Mean apnoea dur s & $21.0 \pm 1.2$ & $23.5 \pm 1.1 * *$ \\
\hline \multicolumn{3}{|l|}{ Mean hypopnoea } \\
\hline dur $\mathrm{s}$ & $13.5 \pm 0.4$ & $16.3 \pm 0.7 * * *$ \\
\hline Apnoea time $\min$ & $107.2 \pm 15.9$ & $106.9 \pm 13.9$ \\
\hline Mean $\mathrm{A}$ low $\mathrm{SaO}_{2} \%$ & $86 \pm 1.5$ & $86 \pm 1.1$ \\
\hline Mean $\mathrm{H}$ low $\mathrm{SaO}_{2} \%$ & $88 \pm 1.1$ & $89 \pm 0.8$ \\
\hline AHI $<90 \% \mathrm{n} \cdot \mathrm{h}^{-1}$ & $36.5 \pm 6.2$ & $34.6 \pm 5.1$ \\
\hline $\mathrm{AHI}<80 \% \mathrm{n} \cdot \mathrm{h}^{-1}$ & $13.3 \pm 3.7$ & $7.9 \pm 2.0^{+}$ \\
\hline Snoring index $n \cdot h^{-1}$ & $8.6 \pm 1.8$ & $8.4 \pm 1.6$ \\
\hline Mean snoring $\mathrm{SaO}_{2} \%$ & $92 \pm 0.5$ & $92 \pm 0.8$ \\
\hline
\end{tabular}

Data are presented as mean \pm SEM. ***,***: $\mathrm{p}=0.02,0.005,0.001$; $+: p=0.04$; SE: sleep efficiency; REM: rapid eye movement; AI: apnoea index; HI: hypopnoea index; mean A low $\mathrm{SaO}_{2}$ : mean low $\mathrm{SaO}_{2}$ during apnoeas; mean $\mathrm{H}$ low $\mathrm{SaO}_{2}$ : mean low $\mathrm{SaO}_{2}$ during hypopnoeas; $\mathrm{AHI}<90 \%$ : apnoea+hypopnoea index with low $\mathrm{SaO}_{2}$ below $90 \%$; $\mathrm{AHI}<80 \%$ : apnoeas+hypopnoea index with low $\mathrm{SaO}_{2}$ below $80 \%$. For further abbreviations see legend to table 1 . 

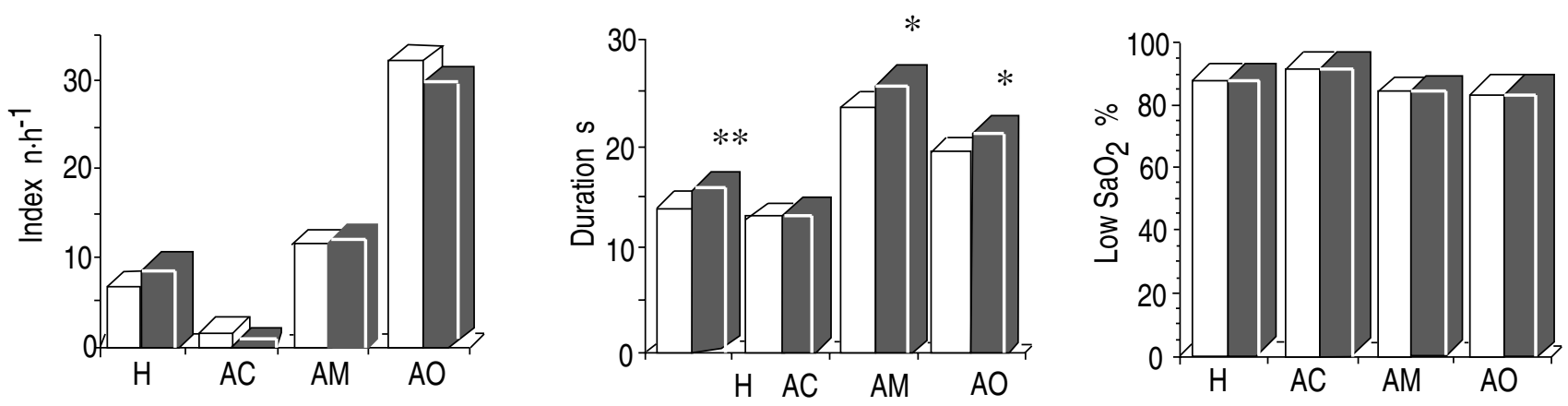

Fig. 1. - Mean values of hypopnoea (H) and central (AC), mixed (AM) and obstructive (AO) apnoea index, duration and desaturation. A significant change at follow-up was found only for hypopnoea, and mixed and obstructive apnoea duration without changes in index and nocturnal hypoxaemia. $\square$ : baseline; $\square$ : follow-up. *: $\mathrm{p}=0.005$, **: $\mathrm{p}=0.001$ follow up $v$ s baseline.

No significant decrease was found for AI, AHI, SI, and mean low saturation, and a nonsignificant increase in HI. A significant increase in apnoea $(\mathrm{p}=0.005)$ and hypopnoea $(\mathrm{p}=0.001)$ duration was present. Considering each type of apnoea (fig. 1), significant differences were found for mixed and obstructive apnoea duration, without significant changes in mean low $\mathrm{SaO}_{2}$ and index. No significant differences were found for $\mathrm{SaO}_{2}$ in awake state, or for mean low saturation during apnoea, hypopnoea and snoring. Considering the AHI $<90 \%$ and $<80 \%$ as indices of severity of hypoxaemia, a mild but significant decrease in $\mathrm{AHI}<80 \%$ was found in the whole study group ( $\mathrm{p}=0.04)$. The AHIS and AHIL were determined in patients whose baseline and follow-up sleep was recorded in lateral and supine posture ( $\mathrm{n}=18$ patients).

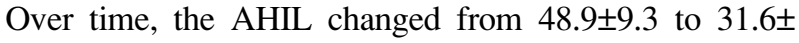
$6.2(\mathrm{p}=0.03)$, and the AHIS from $75.8 \pm 7.3$ to $60.2 \pm 4.8$ $(\mathrm{p}=0.004)$.

No correlation was found between the changes in AHI, AHI $<90 \%$, AHI $<80 \%$, apnoea and hypopnoea mean low $\mathrm{SaO}_{2}$ and age, BMI, AHI, mean low $\mathrm{SaO}_{2}$, pulmonary function tests, $\mathrm{PaO}_{2}, \mathrm{PaCO}_{2}$ at baseline or their changes during the follow-up. Comparison between the "worsened" group and the "improved" group (table 4) showed that those with worsening tended to be younger (52 vs $56 \mathrm{yrs})$, with lower BMI (26.0 vs 28.9), and $\mathrm{PaO}_{2}(79.0$ vs $82.7 \mathrm{mmHg})(10.5$ vs $11.0 \mathrm{kPa}$ ) than the "improved" group at baseline. The "worsened" and "improved" groups significantly differed at baseline in absolute levels of AI (8.7 vs 45.1, $\mathrm{p}=0.001)$, AHI (14.1 vs 56.3, $\mathrm{p}=0.001)$, mean low $\mathrm{SaO}_{2}$ (92 vs 88\%, $\mathrm{p}=0.004)$ and snoring index $(21.4$ vs $3.6, \mathrm{p}=0.001)$. In the "worsened" group the BMI rose from 26.0 to 29.2 ( $\mathrm{p}=0.006$ ), AHI rose from 14.1 to $51.3(\mathrm{p}=0.01)$ and mean low $\mathrm{SaO}_{2}$ decreased from 91.7 to $89.9 \%$ (NS). In the "worsened" group, statistical analysis showed no significant correlation between AHI changes and changes in BMI ( $\mathrm{r}=0.52$, $\mathrm{p}=0.07$ ). The remaining 19 patients ("stable") had no significant changes in diurnal and nocturnal parameters between the first and second evaluation, except for a decrease in AHI $<80 \%(\mathrm{p}=0.03)$.

No significant differences were found in mean sleep latency at baseline and follow-up in the set of patients as a whole, whereas a significant increase $(\mathrm{p}=0.0001)$ was found in the "improved" group.

Table 4. - Mean values of anthropometric and polygraphic parameters at baseline (before) and follow-up (after) in the "worsened" ( $n=7)$, "improved" ( $n=6)$ and "stable" $(n=19)$ OSAS subgroups

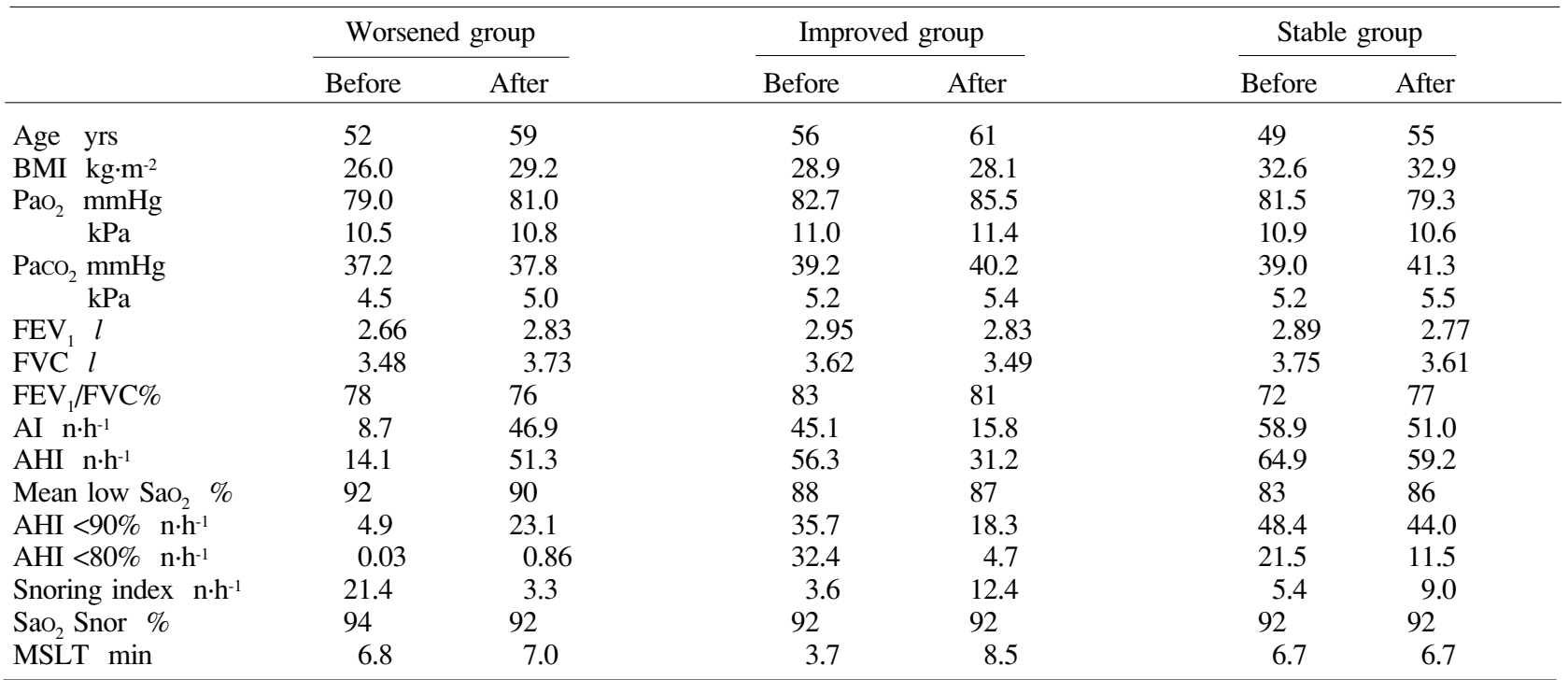

$\mathrm{SaO}_{2}$ Snor: mean $\mathrm{SaO}_{2}$ during snoring. For further abbreviations see legends to tables 1 and 3 . 


\section{Discussion}

Our cohort of subjects who underwent polysomnographic sleep studies between 1984 and 1987 gave us the opportunity to evaluate OSAS patients longitudinally. The current results both contradict and support selected earlier studies on evolution of sleep apnoea syndrome. The most important findings in our study are: 1) untreated OSAS patients show a downward trend in apnoea index and nocturnal oxygen saturation parameters, particularly evident for patients with a more severe syndrome at baseline; 2) MSLT showed a constant upward trend in all subjects, correlated with subjective improvement in sleepiness; 3 ) the reduction or stability of sleep-related breathing disorders were not associated with detectable differences in pulmonary function tests and blood gases analysis. 4) The increased AHI in "worsened" group was not correlated significantly with the increase in BMI.

The most surprising outcome of this study was the unexpected lack of change in respiratory abnormalities, and the absence of expected worsening in apnoea frequency and nocturnal hypoxaemia, suggested by the typical clinical history of OSAS and by the epidemiological surveys. Moreover, there was no significant increase in cardiovascular complications and in hypertensive risk, even in patients with severe hypoxaemia at the time of diagnosis. Data on anthropometric variables, age and disease severity at baseline evaluation were not helpful in determining evolution. However, the "worsened" group differed from the improved group in having a less severe syndrome at baseline. One explanation for our results is that these parameters vary widely, and it would take a larger series to show differences over time for mild and severe patients.

The composition of our group and the methods inherent in the study deserve some comment. Firstly, the sample of patients in the final group was small and older, thus, unlikely to be representative of a randomly selected population. As our subjects accepted polygraphic follow-up, they may have been those who were still most affected in terms of snoring. However, clinical examination of the group refusing follow-up disclosed that the incidence of cardiovascular complications and the improvement of subjective symptoms were similar to the study group. Secondly, changes in general condition, medication or alcohol intake are more likely to occur in the longer interval and possibly influence our results. Unfortunately, we cannot discuss the effects of these factors due to the absence of quantitative evaluation at the time of diagnosis. Finally, a limitation of prospective and retrospective studies is the influence of intersubject and internight variability in apnoea index on the final results $[8,9]$. The first night effect due to sleep laboratory environment may explain the internight variability. In our study, there were no differences in the setting of the two studies. Moreover, because of the long interval, the changes seen are probably not simply the results of better acclimatization to the laboratory.

Night-to-night variability exists in OSAS patients, with higher levels of variability particularly in those subjects with mild apnoea. Even if this effect cannot be excluded in our study, a reduction in apnoea frequency and nocturnal hypoxaemia was found in our patients, even in those with a more severe syndrome at the time of the first evaluation. Moreover, when comparing our subgroups of patients, the improvement or stability in apnoea frequency was greater in those patients with a higher AHI at baseline. Another major factor implicated in the internight variability is the change in upper airway resistance and sleep apnoea in the supine position. Because a reduced $\mathrm{AHI}$ in the supine and lateral positions was found in 18 patients whose sleep position was defined in the two polygraphic studies, we feel that the changes in body position alone are unlikely to have contributed significantly to our results.

We are uncertain whether our results are due to the natural history of sleep apnoea syndrome or simply a reflection of different medical and environmental factors. Conflicting results are also present in the literature. A recent report [10], studying 42 patients at least 6 months after the first investigation, found a significant worsening of the syndrome, with a rapid progression in apnoea frequency and nocturnal hypoxaemia. In this study, full polysomnography was performed only in patients with an apnoea index $>5$, and the first examination was performed by a screening recording method. Because of the selection of patients, the short duration of follow-up, and the method of recording, one should be cautious with these conclusions. We performed a similar all-night polygraphic study, and selected patients with different syndrome severity to evaluate a different evolution in mild or severe cases in the same conditions. A previous long-term report [6], examining mild cases of OSAS 15 months after diagnosis, showed no significant worsening of the syndrome in the absence of BMI changes. Our results in part confirm these findings not only in mild subjects but also in severe patients.

Any interpretation of retrospective and prospective studies must be regarded in the light of the complex interference of diurnal parameters. It is known that age, gender, obesity and pulmonary function are considered risk factors for snoring and cardiovascular morbidity. Our results do not establish any of these factors as predicting the evolution of the syndrome in the group of patients. However, the effect of weight, lung function and age cannot be ruled out.

Our results raise the question of the role of BMI in the observed changes in AHI. In the group of subjects as a whole and in "stable" and "improved" subgroups no significant changes in BMI were found even in the absence of conservative therapy. In the "worsened" subgroup the increase in weight did not correlate significantly with the changes in AHI. Thus, no definite conclusion can be drawn for the effect of weight in the evolution of the syndrome in our study population.

The role of lung function and blood gas concentrations in the severity of OSAS and in the genesis of cardiopulmonary sequelae is controversial. One study, examining the relationship between these factors and AI, failed to find any significant correlation [11]. However, other studies $[12,13]$ have shown that lower forced expiratory volumes in one second $\left(\mathrm{FEV}_{1}\right)$, lower forced vital capacity $(\mathrm{FVC}$,) and diurnal hypoxaemia and hypercapnia, 
play a primary role in the development of right heart failure and pulmonary hypertension. Analysis of diurnal parameters showed no deterioration in $\mathrm{PaO}_{2}, \mathrm{PaCO}_{2}$ and spirometry in any of our patients.

According to epidemiological studies, the prevalence of OSAS among adult men is about $1-2.7 \%$ with an agerelationship, so that the prevalence among adult men aged 40-65 yrs may be over 5\% [14, 15]. Moreover, the risk of hypertension, obesity, and severe sleep apnoea occurs more often in younger patients [11], in whom the onset of snoring started early in the second decade of life [16]. Only a few patients over 58 yrs developed severe OSAS and hypertension [11]. Even though our population had no significant correlations between age and changes in AHI, the "worsened" and "stable" group presented a lower age at baseline, in comparison to the "improved" group. Thus, the decrease in AHI and severity of nocturnal hypoxaemia found in our subjects may be explained by the natural regression of the syndrome in the older patients.

The aim of this study was to determine whether OSAS naturally tended to worsen in untreated patients. The question is an important one, since it justifies prompt therapy to prevent cardiovascular sequelae even in mild or asymptomatic patients.

In our population, neither AI, AHI or nocturnal hypoxaemia significantly worsened over time. We failed to find any daytime or nocturnal parameters as predictive or responsible for the natural trend of sleep apnoea syndrome. Further studies in a larger population are required to determine the nocturnal and diurnal parameters underlying the temporal trend of evolution of the OSAS.

Acknowledgements: The authors thank N. Bertozzi and G. Caltabiano for their technical assistance, and P.L. Lenzi for statistical analysis.

\section{References}

1. He J, Kryger MH, Conway W, Roth T. Mortality and apnea index in obstructive sleep apnea. Chest 1988; 94: 9-14.

2. Jeong DU, Dimsdale JE. Sleep apnea and essential hypertension: a critical review of the epidemiological evidence for comorbidity. Clin Exp Hypertension (A) 1989; 11: 1301-1323.
3. Hoffstein V, Rubinstein I, Mateika S, Slutsky AS. Determinants of blood pressure in snorers. Lancet 1988; i: 992-994.

4. Roth T, Roehrs T, Kryger M. Mortality in sleep apnea. In: Issa FG, Suratt PM, Remmers JE, eds. Sleep and Respiration. New York, Wiley-Liss, 1990; pp. 347-352.

5. Partinen M, Guilleminault C. Daytime sleepiness and vascular morbidity at seven year follow-up in obstructive sleep apnea patients. Chest 1990; 97: 27-32.

6. Zorick FJ, Roerhrs TA, Rosenthal LD, et al. Natural course of sleep apnea: a preliminary report. Association of Professional Sleep Societies. $4^{\text {th }}$ Annual Meeting, 1990; A228.

7. Rechschaffen A, Kales A. A manual of standardized terminology, techniques and scoring system for sleep stages of human subjects. Los Angeles, UCLA, 1968.

8. Wittig RM, Romaker A, Zorick E, Roehrs TA, Conway TA, Roth T. Night-to-night consistency of apnea during sleep. Am Rev Respir Dis 1984; 129: 244-246.

9. Bliwise DL, Benkert RE, Ingham RH. Factors associated with nightly variability in sleep-disordered breathing in the elderly. Chest 1991; 100: 973-976.

10. Svanborg E, Larsson H. Natural evolution of obstructive sleep apnea syndrome. Sleep Res 1992; 1 (Suppl. 1): 224.

11. Peter JH, Faust M, Ploch T, Schultze B. Symptoms and findings in 489 out-patients with suspected sleep apnea. In: Peter JH, Penzel T, Podszus T, von Wichert P, eds. Sleep and Health Risk. Berlin, Springer-Verlag, 1991; pp. 101-107.

12. Bradley TD, Rutherford R, Grossman RF, et al. Role of daytime hypoxemia in the pathogenesis of right heart failure in the obstructive sleep apnea. Am Rev Respir Dis 1985; 131: 835-839.

13. Krieger J, Sforza E, Apprill M, Lampert E, Weitzenblum E, Ratamaharo J. Pulmonary hypertension, hypoxemia and hypercapnia in obstructive sleep apnea patients. Chest 1989; 96: 729-737.

14. Gislason T, Almqvist M, Eriksson G, Taube A, Boman G. Prevalence of sleep apnea syndrome among Swedish men: an epidemiological study. J Clin Epidemiol 1988; 41: 571-576.

15. Cirignotta F, D'Alessandro R, Partinen M, et al. Prevalence of every night snoring and obstructive sleep apnoeas among 30-69 year old men in Bologna, Italy. Acta Neurol Scand 1989; 79: 366-372.

16. Lugaresi E, Cirignotta F, Gerardi R, Montagna P. Snoring and sleep apnea: natural history of heavy snorers disease. In: Guilleminault C, Partinen M, eds. Obstructive Sleep Apnea Syndrome. Clinical Research and Treatment. New York, Raven Press, 1990; pp. 25-36. 